\title{
CONGENITAL STIPPLED EPIPHYSES
}

BY

\author{
J. N. BRIGGS, J. L. EMERY and R. S. ILLINGWORTH \\ From the Children's Hospital, Sheffield
}

(RECEIVED FOR PUBLICATION FEBRUARY 9, 1953)

Caffey (1950) suggested the term 'congenital stippled epiphyses' for a syndrome consisting of achondroplasia, radiological evidence of discrete centres of calcification in cartilaginous epiphyses, together with cataracts and mental deficiency. The condition was first described by Conradi (1914) under the title 'Chondrodystrophia Foetalis Hypoplastica', and was reviewed by Ford, Schneider and Brandon (1951). Below is a case record, presenting some unusual features, with necropsy findings.

\section{Case Report}

A girl, birth weight $6 \mathrm{lb} .8 \mathrm{oz}$, was born at home, after a normal pregnancy and delivery. The infant was admitted to the Jessop Hospital for Women at the age of 24 hours on account of cyanotic attacks. She was then found to have achondroplasia (Fig. 1), bilateral talipes equinovarus, a dry, wrinkled skin (Fig. 2) and bilateral cataracts. There was a grade 3 systolic murmur heard all over the precordium. She had no further cyanotic attacks, and was discharged, to be followed up in the Baby Clinic.

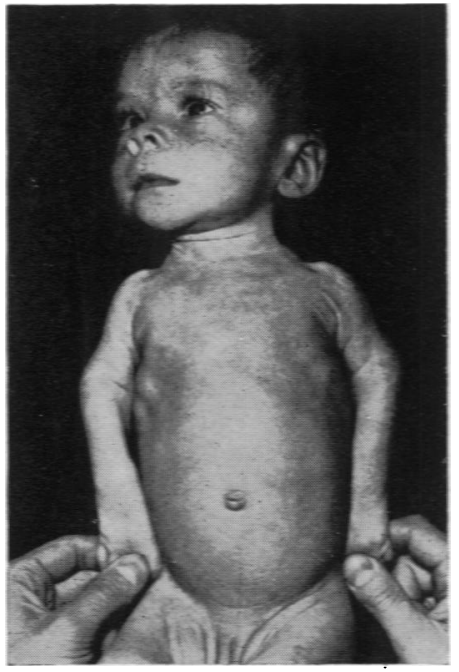

Fig. 1.-Photograph showing achoodro plasia and slightly cretinoid appearance. there was any bony lesion to account for the limited movements of the joints. The radiographs showed stippling of the epiphyses of numerous bones, but no obvious reason for the restricted extension (Figs. 3 and

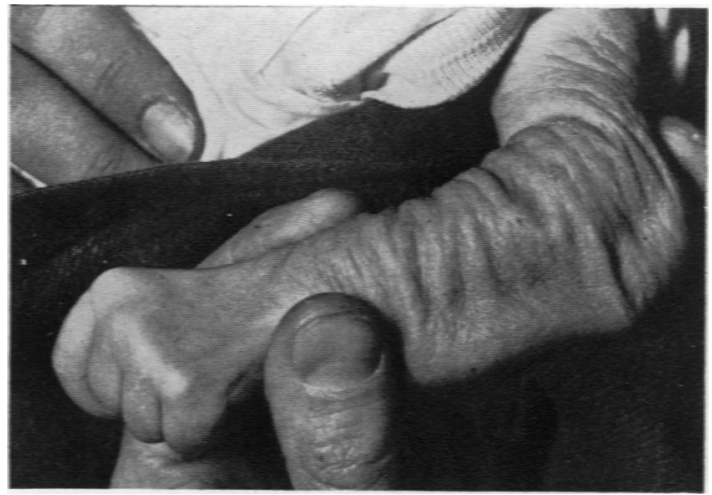

Fig. 2-Dyy wrinkled stin, with flexion deformity of the elbow.

4). The diagnosis of congenital stippled epiphyses was then made.

There was a facial resemblance to cretinism, and the total serum lipoids were found to be $945 \mathrm{mg} . \%$. Other serum chemistry gave serum cakcium level, $11 \cdot 2 \mathrm{mg} . \%$, serum phosphorus level, $4.2 \mathrm{mg} . \%$ serum alkaline phosphatase level, 16.0 units. She was given a six weeks' course of thyroid extract, without effect.

Other findings at the age of 1 month were defective head control when tested in the prone position, in ventral suspension and when pulled to the sitting position, and subluxation at the transverse tarsal joints.

During the next eight months she was followed up in the Baby Clinic, but she made very little physical or developmental progress. She was extremely difficult to feed, not appearing to be hungry, and at the age of 8 months her weight was only $7 \mathrm{lb}$. $3 \mathrm{oz}$. She did not appear to have increased in size at all. There had been hardly any progress in head control, for there was almost complete head lag, and she could only momentarily lift the chin off the couch in the prone position. She took no notice of sound. As she was blind, she could not be tested for eye-following. Vocalizations were very defective and slight. It was clear that she was 
very severely mentally defective. The cardiac murmur had persisted. She died at the age of 9 months of an acute respiratory infection.

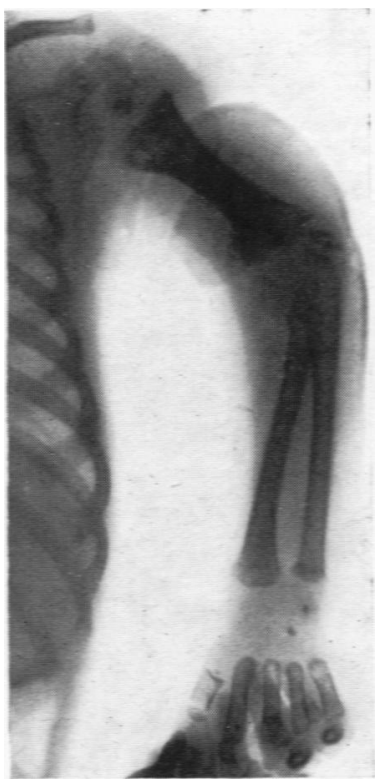

Frg. 3.-Stippling of epiphyses in shoulder, wrist and elbow. The areas of rarefaction in the upper end of the humerus may be enchondroses.

structure. The kidneys were of normal weight. There was bilateral hydronephrosis with the hydro-ureter extending only to the brim of the skeletal pelvis. The eyes showed bilateral cataracts.

In the skeleton the skull was asymmetrical. The width of the ends of the long bones was grossly increased, owing to cartilaginous masses. The joints after removal of muscles could not be fully extended or flexed owing to the presence of these masses. On gross section there was great irregularity in colour and consistency of the epiphysis and some irregularity in the ossification line. The ribs and costal cartilage appeared to be relatively unaffected, as did the small bones of the hands and feet. In the spine the ossification centres were situated anteriorly and
FrG. 4.-Stippling of the epiphysis in the knee joint. posteriorly, with a narrow waist between. The appearance of the spine was identical with the one illus-

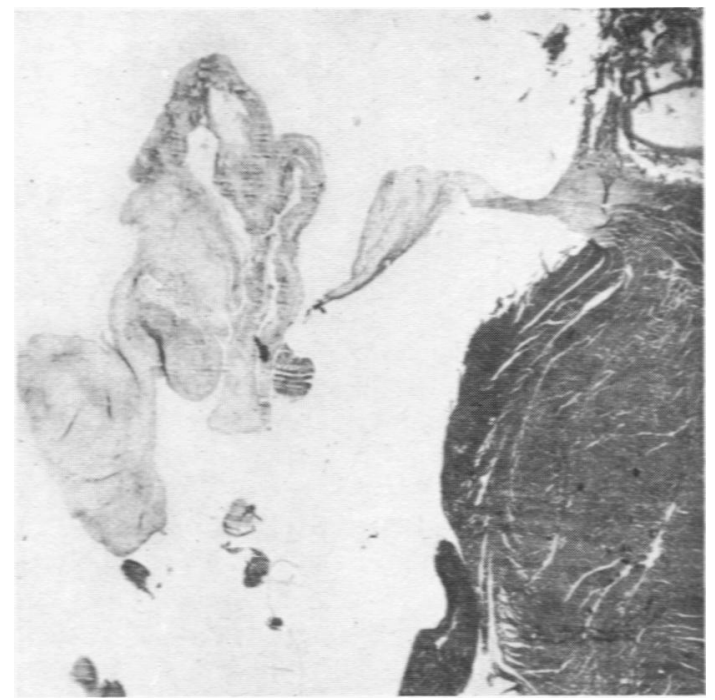

FKG. 5.-Section of the mitral valve showing vegetation on the contact surface. Masson trichrome $\times 14$

trated by Harris in 1933 (Fig. 6). The histological appearance of the cartilage was similar to that illustrated by Harris, the most striking features being the variation in cellular concentration, the great increase in vascularity of the cartilage, and areas of apparent degeneration and primary calcification (Fig. 7). The vessels appeared to penetrate into the cartilaginous mass from the immediate joint surface. The ossification line in the rib, in the ends of the long bones and in the toes showed no specific abnormality. The cartilages of the toes and ribs appeared normal. No abnormality of structure was seen in the thyroid, ovary, retina, pancreas, adrenal, parathyroid, pituitary, brain and spinal cord. The lenses of the eyes were not examined histologically.

\section{Discussion}

The anatomical features of this case are similar to those seen by others, but this child also had a congenital cardiac deformity and hydronephrosis with hydro-ureter.

Reilly and Smyth (1938) suggested that there was a connexion between congenital stippled epiphyses and cretinism. In this case the clinical impression of hypothyroidism, though supported by the finding of high total serum lipoids (947 mg. \%), was not supported by response to treatment or by histological changes in the thyroid gland.

Much of the stippling in the epiphysis is due to calcification of apparently ischaemic areas of cartilage and not to the normal processes such as those in cretinism, but to abnormal growth of cartilage. 


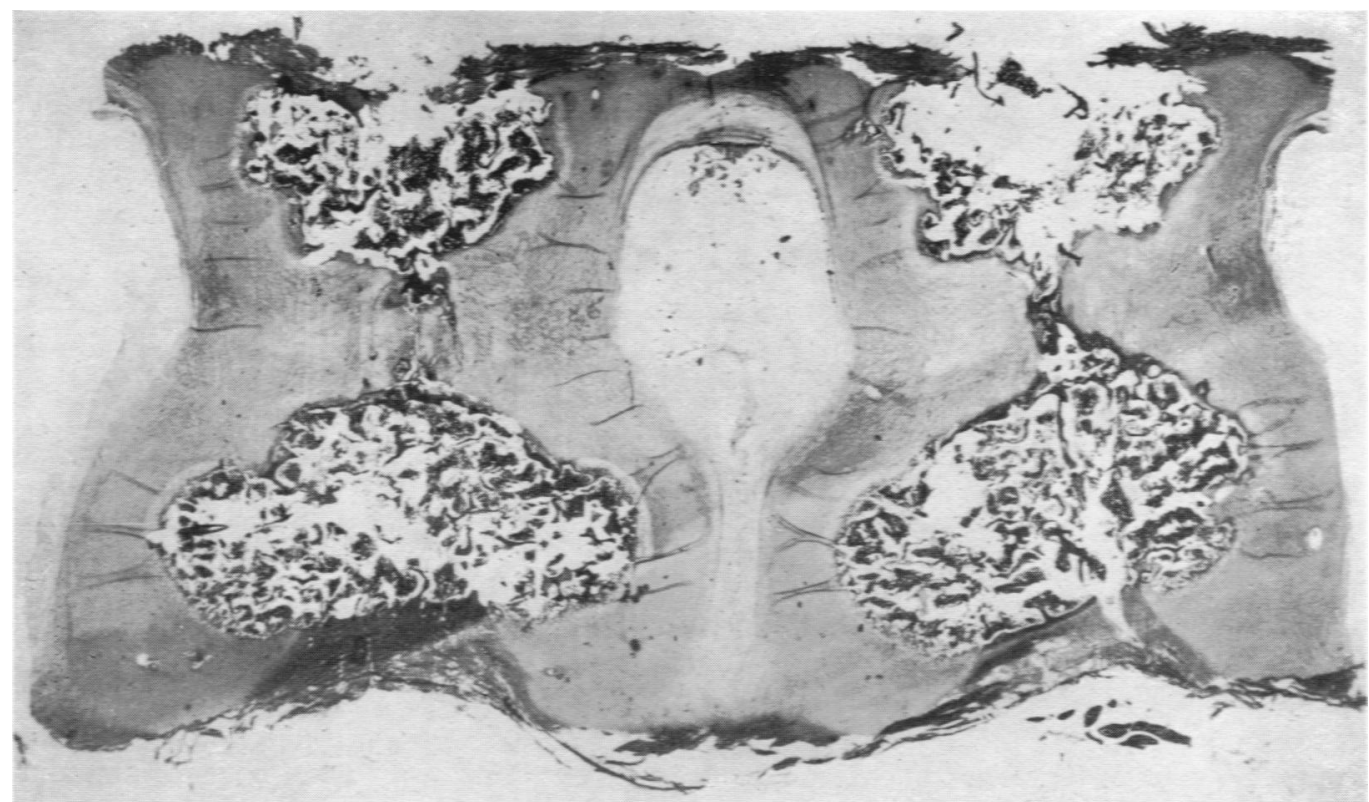

Fig. 6.-Antero-posterior section of two vertical bodies showing the dumbell-shaped ossification. Masson trichrome $\times 5$.

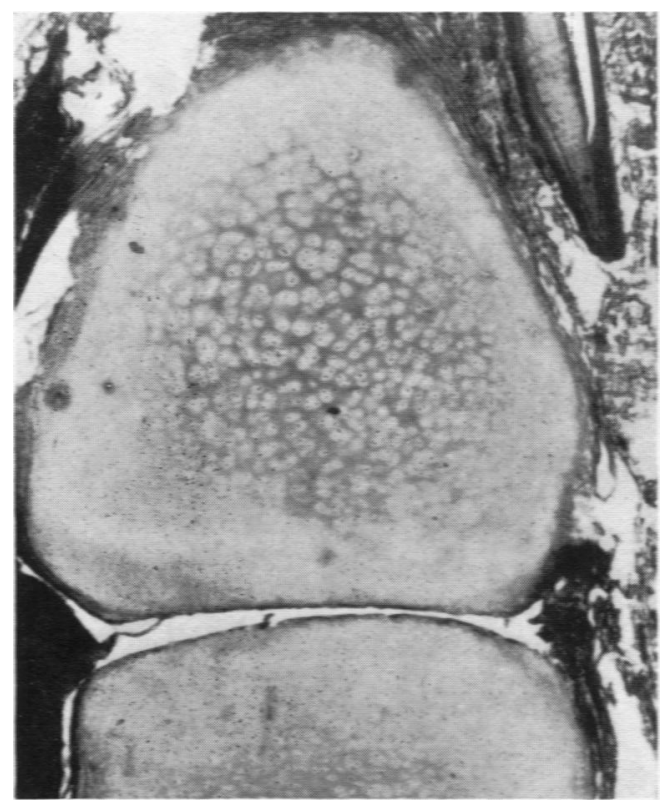

F1G. 7.- Section of cartilaginous mass at the head of the humerus showing gross abnormality of structure. Masson trichrome $\times 7$.

The changes in staining properties of zones of cartilage, which Harris (1933) describes as 'mucoid', seem to us to be not a primary disturbance but merely a stage in degeneration of cartilage preceding calcification, such as is seen in many

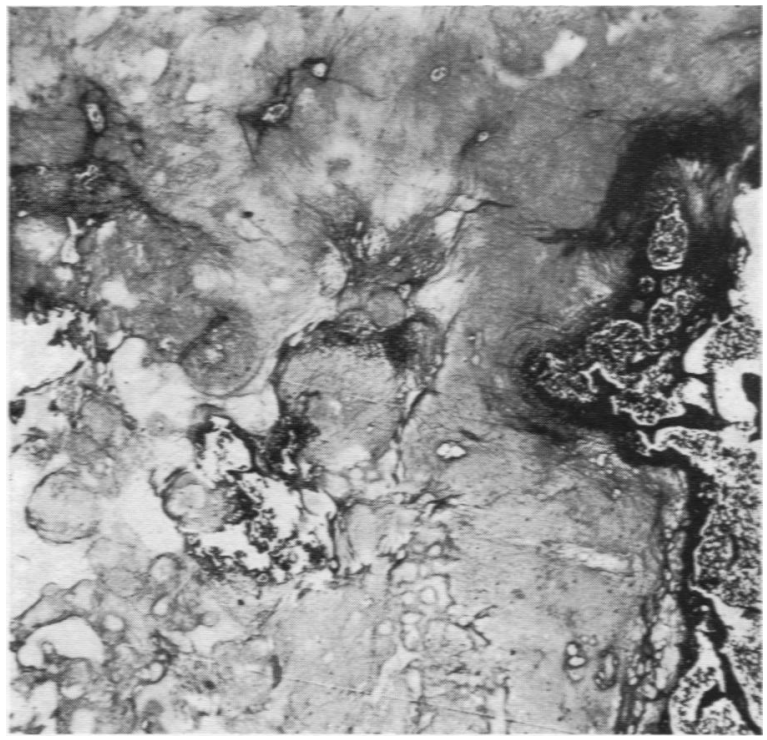

FiG. 8.- Section of the terminal joint of a toe showing normal cartilage and joint. Masson trichrome 36.

deformities or tumours of cartilage (Willis, 1948).

The disease affects apparently only the bones in which secondary centres of ossification in the epiphysis would be likely to develop in utero. The 


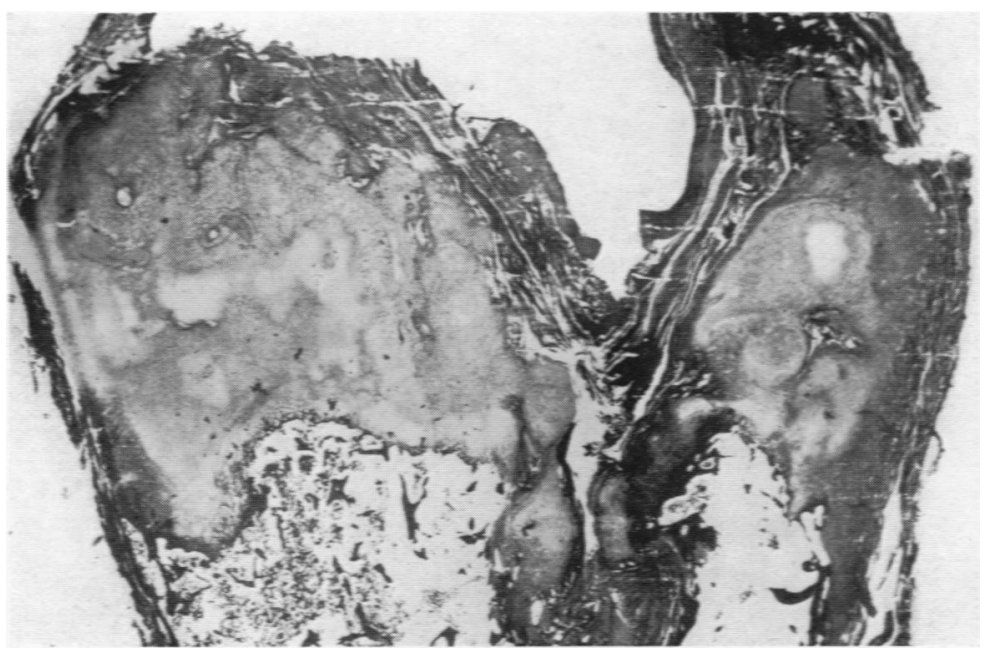

Frg. 9.- Section of the upper end of the tibia showing a tongue of cartilage within the shaft of the bone. Masson trichrome $\times 6$.

ends of the bones of the toes have completely normal cartilage (Fig. 8).

The abnormality in growth of the cartilage in this case appear to be similar in type to the chondrodysplasias, differing from them chiefly in the distribution of the abnormality in cartilaginous growth rather than in underlying structure. There is great variation within the chondrodysplasias themselves (Cole, 1926), but Fairbank (1927), on account of the distribution of atypical cartilage as seen radiologically, considers that cases of stippled epiphysis should not be included in the chondrodysplasias. In the present case there were some irregular masses of cartilage ('enchondrosis') penetrating into the shaft of the long bones (Fig. 9). Another abnormality of cartilage growth with a very similar distribution to the present case, multiple enchondroses, is believed by Speiser (1925) to be due to a fault in development occurring between the fourth and eighth month of foetal life. The abnormal vascularity of the cartilage in the present case is interesting in view of Bentzon's theory (1924) that unusual vascularity is the primary disorder in Ollier's disease or chondrodysplasia (Hunter and Wiles, 1935).

This child showed deformities of the mesenchymal tissue in the renal tract, the heart, and in the lens of the eye as well as in cartilage. This suggests to us, not that this child showed a particular syndrome or disease of connective tissue, but that the condition was due to some intra-uterine disturbance.

Our thanks are due to Dr. T. Lodge for the radiographs, to Miss Finch for the biochemistry, and to Mr. A. N. Tunstill, for the photographs.

\section{REFERENCES}

Bentzon. P. G. K. (1924). Acta radiol., Stockh., 3, 89.

Caffey, J. (1950). Pediatric X-ray Diagnosis, 2nd edit., p. 637.

Cole, W. H. (1926). Sung. Gynec. Obstet., 42, 359.

Conradi, E. (1914). Jb. Kinderheilk., 80, 86. Quoted by Raap, G. (1943). Amer. J. Roentgend., 49, 77

Fairbank, H. A. T. (1927). Brit. J. Surg., 15, 127.

Ford, G. D., Schneider, M. and Brandon, J. R. (1951). Pediatrics, 8, 380.

Harris, H. A. (1933). Bone Growth in Health and Disease, p. 159.

Hunter, D. and Wiles, P. (1935). Brit. J. Surg., 22, 507.

Reilly, W. A. and Smyth, F. S. (1938). Amer. J. Roentgenol., 40, 675.

Speiser, F. (1925), Virchows Arch., 258, 126.

Willis, R. A. (1948). Pathology of Tumours, p. 670. London. 